\title{
Strain-dependent interactions of Streptococcus gallolyticus subsp. gallolyticus with human blood cells
}

\author{
Imke Grimm ${ }^{\dagger}$, Melanie Weinstock ${ }^{\dagger}$ Ingvild Birschmann, Jens Dreier, Cornelius Knabbe and Tanja Vollmer (D)
}

\begin{abstract}
Background: Streptococcus gallolyticus subsp. gallolyticus (S. gallolyticus) is the causative pathogen in up to 20\% of streptococcal-induced infective endocarditis (IE) cases. However, the underlying mechanisms of pathogenesis in $S$. gallolyticus have not yet been solved. Pathogens causing IE need to employ virulent strategies to initiate and establish infections, such as escape the bloodstream, invade the host-cell, and persist intracellularly. In this study, we examined the induction of inflammation by different S. gallolyticus strains in relation to their survival in whole blood and cell culture models as well as their ability to induce platelet aggregation. Phagocytosis of these bacteria by macrophages, followed by intracellular survival, was also quantified.
\end{abstract}

Methods: In whole blood and THP-1 cell culture assays bacterial growth kinetics was determined by plating, followed by colony counting. Induction of interleukin (IL)-6 expression in whole blood of three healthy volunteers, caused by different strains, was quantified by ELISA. Gene expression of cytokines (ILIB, IL6 and IL8) was quantified by real-time PCR after stimulating THP-1 monocytes with bacteria. Induction of platelet aggregation was analyzed by light transmission aggregometry using the BORN method. A macrophage model was used to analyze phagocytosis of strains and their survival in macrophages within $48 \mathrm{~h}$.

Results: Strains promoted IL-6 secretion in a time-dependent fashion. For example, DSM16831 induced IL-6 secretion in whole blood earlier than other isolates, and was eliminated in the whole blood of one volunteer, whereas UCN34 could grow. Platelet aggregation depended on the different isolates used and on the individual platelet donor. Two strains (AC1181 and 010672/01) induced cytokine gene expression in THP-1 monocytes only marginally, compared to other strains. The phagocytosis rate of S. gallolyticus isolates differed significantly, and the isolates UCN34 and BAA-2069 could persist for a considerable time in the phagocytes.

Conclusion: The strain-dependent differences of S. gallolyticus isolates, observed during interaction with human blood cells, support the hypotheses that divergences in individual virulence factors determine a distinct pathogenicity of the isolates. These data constitute an additional step towards the elucidation of mechanisms in the complex, multifactorial pathogenesis of this IE pathogen.

Keywords: S. gallolyticus subsp. Gallolyticus, Infective endocarditis, Platelet aggregation, Whole blood assay, THP-1 monocytes, Phagocytosis

\footnotetext{
* Correspondence: tvollmer@hdz-nrw.de

${ }^{\dagger}$ Equal contributors

Institut für Laboratoriums- und Transfusionsmedizin, Herz- und

Diabeteszentrum Nordrhein-Westfalen, Universitätsklinikum der

Ruhr-Universität Bochum, Bad Oeynhausen, Germany
}

(c) The Author(s). 2017 Open Access This article is distributed under the terms of the Creative Commons Attribution 4.0 International License (http://creativecommons.org/licenses/by/4.0/), which permits unrestricted use, distribution, and reproduction in any medium, provided you give appropriate credit to the original author(s) and the source, provide a link to the Creative Commons license, and indicate if changes were made. The Creative Commons Public Domain Dedication waiver (http://creativecommons.org/publicdomain/zero/1.0/) applies to the data made available in this article, unless otherwise stated. 


\section{Background}

Streptococcus gallolyticus subsp. gallolyticus (formerly Streptococcus bovis biotype I) is a frequent pathogen in infective endocarditis (IE) [1] Furthermore, an association of S. gallolyticus subsp. gallolyticus-induced IE with colorectal malignancies has been observed in many cases [2-4]. Boleij et al. suggested a novel pathophysiological link between IE caused by $S$. gallolyticus subsp. gallolyticus and colorectal cancer, in which S. gallolyticus subsp. gallolyticus translocates through the adenomatous colon epithelium paracellular, followed by transport within the bloodstream towards the heart [5]. For IE pathogens, the adhesion to and/or invasion of endothelial cells of the endocardium is the first step in the establishment of vegetation. S. gallolyticus subsp. gallolyticus isolates have already been shown to have straindependent properties to adhere to or invade endothelial cells $[6,7]$.

Additionally, the interaction of S. gallolyticus subsp. gallolyticus with cells of the innate immune system plays an important role for survival in the host. It is initiated by bacterial pathogen-associated molecular patterns, which are detected by pathogen-recognition receptors to activate the innate immunity and counteract the infection [8]. Differences in virulence genes could provoke divergent strain-specific interactions with inflammatory cells and the induction of an inflammatory response during the transport of these bacteria within the bloodstream, potentially resulting in a significant difference in their ability to cause infection.

The pro-inflammatory cytokines, tumor necrosis factor$\alpha$ (TNF- $\alpha$ ), interleukin-1 $\beta$ (IL-1 $\beta$ ) and IL-6, are the first secreted cytokines in a local infection, such as IE $[9,10]$. Animal studies have suggested an intriguing role of IL-6 in the establishment of various infections [11-13]. Bustamante et al. showed an association between the inflammatory response, related to IL-6 and IL-8 cytokine profiles, and the outcome of an IE prosthetic valve endocarditis [14]. We, therefore, aimed to elucidate whether $S$. gallolyticus subsp. gallolyticus could provoke cytokine response in a strain-dependent manner from THP-1 monocytes and in a whole blood model. We reasoned that the potential of cytokine induction by different S. gallolyticus subsp. gallolyticus isolates could offer new insights into host-pathogen interaction. Because of the critical role of IL- 6 in IE, the induction of IL-6 secretion was analyzed in whole blood. Monocytes are one of the first cells at an infection site and play a pivotal role in inflammatory response and recruitment of further immune cells [15-17]. Whereas IL- $1 \beta$ and TNF- $\alpha$ are the first cytokines in an infection and are generally pro-inflammatory [10], IL-6 is secreted thereafter and acts in both pro- and antiinflammatory roles [18]. IL-8 and monocyte chemoattractant protein-1 (MCP-1) belong to the chemokine family and recruit more monocytes and other immune cells to the site of infection [19]. Thus, we analyzed the stimulation of expression of the IL- $1 \beta$ and IL- 6 genes, and subsequently, that of IL-8, by S. gallolyticus subsp. gallolyticus, in THP-1 monocytes. Additionally, the survival of S. gallolyticus subsp. gallolyticus was also analyzed in this model.

Platelet aggregation in an IE acts like a double-edged sword; on one hand, platelets are anti-infective, releasing antimicrobial peptides and inflammatory mediators [20], and on the other hand, aggregated platelets and fibrin mask bacteria at the site of infection, which protects them from other immune cells in the tissue and blood [21]. The interaction of pathogens with platelets has been described as a virulence factor, and several pathogens are well-characterized for their relative potential to induce the aggregation of platelets [21-23]. Veloso et al. revealed that $S$. gallolyticus subsp. gallolyticus induces platelet aggregation rapidly, compared to Enterococcus feacalis [24]. Regarding the potential of bacteria to induce platelet aggregation as a virulence factor, our study has focused on determining whether strain-dependent differences in the induction potential can be revealed.

Finally, macrophages play a key role in innate immunity during an IE. Five percent of the surface of heart valve tissues infected by Streptococcus species is covered with macrophages [17]. It has already been shown that the S. gallolyticus subsp. gallolyticus isolate (UCN34) could survive much longer in macrophages compared to other bacteria (e.g. Bacillus subtilis) [5]. In the present study, we analyzed and compared the phagocytosis by macrophages and the survival of different S. gallolyticus subsp. gallolyticus strains in a cell culture model.

\section{Methods}

\section{Cell culture and bacterial strains}

THP-1 cells (ATCC, Wesel, Germany) were cultivated in Dulbecco's modified Eagle's medium (DMEM, Thermo Scientific, Waltham, USA) supplemented with 10\% fetal calf serum (FCS, Pan Biotech, Aidenbach, Germany) and antibiotic/antimycotic solution (AB/AM, PAA Laboratories, Cölbe, Germany) at $37{ }^{\circ} \mathrm{C}$ and $5 \% \mathrm{CO}_{2}$. S. gallolyticus subsp. gallolyticus strains, and Staphylococcus aureus for comparison (Table 1), were grown overnight in brain-heart infusion broth (Oxoid, Wesel, Germany) at $37{ }^{\circ} \mathrm{C}$ in a rotating shaker at $220 \mathrm{rpm}$. The bacterial titer was determined by serial dilutions in Dulbecco's phosphate-buffered saline (DPBS) and plating $100 \mu \mathrm{l}$ of an appropriate dilution on tryptone soya agar (Oxoid, Wesel, Germany) in triplicates for colony count.

\section{Whole blood assay and measurement of IL-6}

Inoculation of whole blood with S. gallolyticus subsp. gallolyticus strains was performed with human blood from three healthy volunteers. Blood was collected in 
Table 1 Bacterial strains: S. gallolyticus subsp. gallolyticus strains and Staphylococcus aureus

\begin{tabular}{llll}
\hline Species & Strain & Source & Origin \\
\hline S. gallolyticus subsp. gallolyticus & DSM16831 & animal & DSMZ \\
S. gallolyticus subsp. gallolyticus & DSM13808 & sapropel & DSMZ \\
S. gallolyticus subsp. gallolyticus & isolate 010672/01 & human, IE patient & HDZ, Germany \\
S. gallolyticus subsp. gallolyticus & Isolate 021702/06 & human, IE patient & HDZ, Germany \\
S. gallolyticus subsp. gallolyticus & BAA-2069 & human, IE patient & HDZ, Germany \\
S. gallolyticus subsp. gallolyticus & AC1181 & human & RWTH Aachen \\
S. gallolyticus subsp. gallolyticus & AC6827 & human & RWTH Aachen \\
S. gallolyticus subsp. gallolyticus & LMG17956 & animal & Netherlands \\
S. gallolyticus subsp. gallolyticus & UCN34 & human, IE patient & Calvados, France [50] \\
S. aureus & ATCC25923 & Human & ATCC [51] \\
\hline
\end{tabular}

DSMZ German Collection of Microorganisms and Cell cultures, RWTH Aachen RWTH Aachen University, LMG Laboratory of Microbiology, Ghent University, HDZ Heart and Diabetes Center NRW, ATCC American Type Culture Collection

heparin-gel monovettes (Kabe, Nümbrecht-Elsenroth, Germany) and mixed with RPMI1640 with or without $S$. gallolyticus subsp. gallolyticus from overnight cultures (initial bacterial titer: 1.6-4.8 × 10 $0^{5}$ colony-forming units $(\mathrm{CFU}) / \mathrm{ml}$; volume ratio $1: 10)$, as described previously [25]. Suspensions were incubated in 6-well plates at $37^{\circ}$ $\mathrm{C}$ and $5 \% \mathrm{CO}_{2}$. Aliquots of $500 \mu \mathrm{l}$ samples from either bacterial, blood or medium suspensions were used for the plating assay after $0,6,24$ and $48 \mathrm{~h}$. The experiment was performed on two different days with three technical replicates/day/volunteer. The residual probes were centrifuged at $1000 \times g$ for $5 \mathrm{~min}$ and the supernatant was used for the measurement of IL- 6 with a human IL-6 enzyme-linked immunosorbent assay (ELISA; Thermo Scientific, Waltham, USA), following the manufacturer's instructions. Cell viability of leukocytes in whole blood was determined by flow cytometry (FACSCanto II; BD Biosciences, San José, USA) after lysis of the erythrocytes with BD Viaprobe (1:200).

\section{Quantification of inflammatory response of THP-1 cells upon infection by $S$. gallolyticus subsp. gallolyticus}

THP-1 cells were counted with a Neubauer chamber and adjusted to $2 \times 10^{6}$ cells/ml in DMEM with $10 \%$ FCS. Overnight cultures of bacteria were washed and diluted to approximately $10^{5} \mathrm{CFU} / \mathrm{ml}$ in DMEM and an aliquot was used for counting bacteria by plating and CFU assay. The cells were either inoculated with $S$. gallolyticus subsp. gallolyticus strains, with lipoteichoic acid (LTA, Sigma Aldrich, Darmstadt, Germany) as a positive control, or with DMEM medium as a negative control for $6 \mathrm{~h}$. Afterwards, an aliquot of $100 \mu \mathrm{l}$ was used for counting bacteria by plating assay. As before, the experiment was performed at 3 different days, with three technical replicates per day. For gene expression analysis, $2 \mathrm{ml}$ sample was centrifuged at 10,000 rpm for $5 \mathrm{~min}$ and the THP-1 cell pellet was lysed with $600 \mu \mathrm{l}$
RA1 buffer of the NucleoSpin RNAII kit (MarcheryNagel, Düren, Germany).

\section{Gene expression analysis of THP-1 cells}

Isolation of RNA was performed with the NucleoSpin RNA II kit, following the manufacturer's instructions. The RNA was eluted with $25 \mu \mathrm{l}$ RNase-free water and quantified using the NanoDrop 2000 (PeqLab, Erlangen, Germany). For the synthesis of cDNA, $2 \mu \mathrm{g}$ RNA were diluted in $20 \mu \mathrm{l}$ RNase-free water and cDNA synthesis was performed using the Superscript II Reverse Transcriptase Kit (Invitrogen, Carlsbad, USA), following the manufacturer's instructions. The cDNA was used for relative quantitative real-time PCR. Real-time DNA amplification was measured on the Mastercycler ep Realplex platform (Eppendorf, Hamburg, Germany) using the Platinum SYBR Green qPCR SuperMix-UDG (Invitrogen, Carlsbad, USA). A volume of $10 \mu \mathrm{l}$ was used for each reaction that contained $2.5 \mu \mathrm{l}$ cDNA (dilution 1:5), $0.25 \mu \mathrm{l}$ each Primer (20 $\mu \mathrm{M}), 5.0 \mu \mathrm{l}$ Platinum SYBR Green reaction mix and $2.0 \mu \mathrm{l}$ water, and three replicates were run per sample. Cycling conditions were as follows: degradation of uracil containing DNA at $50{ }^{\circ} \mathrm{C}$ for $120 \mathrm{~s}$, initial denaturation at $95^{\circ} \mathrm{C}(120 \mathrm{~s}), 45$ cycles consisting of denaturation for $10 \mathrm{~s}$ at $95^{\circ} \mathrm{C}$, annealing at $58{ }^{\circ} \mathrm{C}$ for $15 \mathrm{~s}$, and elongation at $72{ }^{\circ} \mathrm{C}$ for $20 \mathrm{~s}$. Additionally, a melting curve served as a control for PCR amplification. Relative gene expression was calculated by normalization to hypoxanthine phosphoribosyltransferase 1 , and glyceraldehyde3-phosphate dehydrogenase by the efficiency-corrected $\Delta \Delta$ ct method [26]. Sequences of the intron-spanning oligonucleotides for the reference genes hypoxanthine phosphoribosyltransferase 1 and glyceraldehyde-3-phosphate dehydrogenase and the genes of interest (IL1B, IL6 and IL8) are listed in Table 2. 
Table 2 Sequences of oligonucleotides used for relative quantification in real-time PCR

\begin{tabular}{|c|c|}
\hline Gene name & $\begin{array}{l}\left.\text { Forward primer ( } 5^{\prime} \text { to } 3^{\prime}\right) \text { Reverse } \\
\left.\text { primer (5' to } 3^{\prime}\right)\end{array}$ \\
\hline \multirow[t]{2}{*}{ Interleukin-1 $\beta$ (IL1B), } & ACAGATGAAGTGCTCCTTCCA \\
\hline & GTCGGAGATTCGTAGCTGGAT \\
\hline \multirow[t]{2}{*}{ Interleukin-6 (IL6) } & ACAGCCACTCACCTCTTCAG \\
\hline & GTGCCTCTITGCTGCTITCAC \\
\hline \multirow[t]{2}{*}{ Interleukin-8 (IL8) } & GAACTGAGAGTGATTGAGAGTGGA \\
\hline & СТСТTCAAAAACTTCTCCACAACC \\
\hline \multirow{2}{*}{$\begin{array}{l}\text { Hypoxanthine } \\
\text { phosphoribosyltransferase } \\
1 \text { (HPRT) }\end{array}$} & GCTGACCTGCTGGATTAC \\
\hline & TGCGACCTTGACCATCTT \\
\hline \multirow{2}{*}{$\begin{array}{l}\text { Glyceraldehyde-3-phosphate } \\
\text { dehydrogenase (GAPDH) }\end{array}$} & AGGTCGGAGTCAACGGAT \\
\hline & TCCTGGAAGATGGTGATG \\
\hline
\end{tabular}

\section{Platelet aggregation assay}

Platelet aggregation was performed with platelet-rich plasma (PRP) of three healthy volunteers by light transmission aggregometry using the BORN method [27]. Blood was collected in PFA monovettes. The PRP was achieved by centrifugation $(250 \times g, 15 \mathrm{~min}$ without a break). Platelet-poor plasma was achieved by centrifugation of the monovettes at $2770 \times g$ for $5 \mathrm{~min}$. The PRP was diluted up to 200,000 platelets/ $\mu$ within DPBS. Adjustment of the bacterial concentration was performed using the BactiFlow (bioMérieux, Marcy-l'Étoile, France), as described previously [28]. Suspensions (bacteria:platelet $=2: 1$ ) were used for aggregation in the Apact $4 \mathrm{f}$ aggregometer (DiaSys, Holzheim, Germany). Acquisition was performed over $1800 \mathrm{~s}$ and changes of light transmission were acquired with the Apact Software. The experiment was performed on three different days with three technical replicates/day/volunteer.

\section{Phagocytosis assay}

The macrophage assay was based on the phagocytosis assay of Boleij et al. [5] and Kaneko et al. [29]. In brief, THP-1 cells $\left(5 \times 10^{5}\right.$ cell/well $)$ were cultivated in 24-well plates with $50 \mathrm{ng} / \mathrm{ml}$ PMA in cell culture medium, which promoted macrophage differentiation in 3 days. On the third day, the medium was replaced with PMAfree medium after washing the cells twice with DPBS (Thermo Scientific, Waltham, USA). An overnight culture of S. gallolyticus subsp. gallolyticus was serially diluted $\left(10^{3}\right.$ dilution; $\left.10^{5} \mathrm{CFU} / \mathrm{ml}\right)$ in DMEM supplemented with $10 \%$ FCS without $\mathrm{AB} / \mathrm{AM}$ and the final bacterial titer of the inoculum was determined by plating assay. After washing the macrophages with DPBS three times, the $S$. gallolyticus subsp. gallolyticus dilution was added and plates were centrifuged at $400 \times g$ for $5 \mathrm{~min}$ to assure attachment of the bacteria to the macrophages. Phagocytic uptake of bacteria was ensured for $30 \mathrm{~min}$ at
$37{ }^{\circ} \mathrm{C}$ and $5 \% \mathrm{CO}_{2}$, and the macrophages were washed three times with DPBS. DMEM, including 10\% FCS, $1 \times \mathrm{AB} / \mathrm{AM}$ and $200 \mu \mathrm{g} / \mathrm{ml}$ gentamicin, was added for at least $20 \mathrm{~min}$ to kill the residual extracellular bacteria, and this was considered the $0 \mathrm{~h}$ time point [13]. At this time point $(t=0 \mathrm{~h})$, all vital intracellular bacteria are captured. Additionally, the bacterial survival was determined at eight different sampling points $(5,8,12,16,24$, 30,36 and $48 \mathrm{~h}$ ). For each time point, the antibioticsupplemented DMEM-medium was washed away, macrophages were lysed with $1 \%$ saponin and the bacterial titer determined by plating assay. The percentage of bacteria surviving after phagocytosis, was calculated relative to the initial phagocytized bacterial titer (at $\mathrm{t}=0 \mathrm{~h}$ ). The experiment was performed at two different days with four technical replicates per day.

\section{Measurement of cytotoxicity by lactate dehydrogenase release assay}

S. gallolyticus subsp. gallolyticus-mediated cytotoxicity to THP-1 macrophages was detected $5 \mathrm{~h}$ after phagocytosis by measuring the lactate dehydrogenase (LDH) activity in the supernatant. A quantity of $1.3 \times 10^{5}$ THP1 cells were seeded in each well of a 96-well plate in $100 \mu \mathrm{l}$ DMEM supplemented with 10\% FCS, and AB/ AM and differentiation was carried out as described above. The Pierce LDH Assay Kit (Thermo Scientific, Waltham, USA) was used for this analysis. The analysis was carried out following the manufacturer's instructions. The amount of LDH was determined in a Reader Infinite ${ }^{\oplus} \mathrm{m} 200$ PRO microplate reader (Tecan, Männedorf, Switzerland).

\section{Statistics}

Experimental data were analyzed by Mann-Whitney U test using GraphPad Prism 6.0 (GraphPad Software). $P<0.05$ was considered statistically significant. Mean with standard error is displayed in figures.

\section{Results}

Bacterial growth of S. gallolyticus subsp. gallolyticus isolates in a whole blood model

As indicated earlier, S. gallolyticus subsp. gallolyticus must survive in the bloodstream in order to reach the endocardium. To elucidate the survival of different $S$. gallolyticus subsp. gallolyticus strains in whole blood, the bacterial titers were determined after 6,24 and $48 \mathrm{~h}$ of inoculation.

We did not include intermediate time points $(8 \mathrm{~h}$ and $30 \mathrm{~h}$ ) in our routine assays, since they added no additional information regarding the bacterial survival kinetics (data not shown). The cell viability was determined by flow cytometry. About $70 \%$ of the leukocytes were still viable regardless of which sample was observed. The 
bacterial growth was found to be influenced by the blood of the different volunteers and differed between the isolates analyzed (Fig. 1). Specifically, the bacterial titer of strain DSM16831 decreased continuously in the whole blood of volunteer 1 (Fig. 1a). After $48 \mathrm{~h}$ of incubation $\left(2 \times 10^{3} \mathrm{CFU} / \mathrm{ml}\right)$, the titer of volunteer 1 was still low, while the titer of this same isolate in the whole blood of the other volunteers was about ten times higher $\left(3.5 \times 10^{4} \mathrm{CFU} / \mathrm{ml}\right.$; Fig. $1 \mathrm{~b}$ and c). For example, proliferation of DSM16831 was observed in the whole blood of volunteer 2 up to $24 \mathrm{~h}$, but a persistent bacterial titer was noticed in the whole blood of volunteer 3 .

The comparison of strains revealed that strain UCN34 could grow in whole blood during $48 \mathrm{~h}$ of incubation (Fig. 1d). In the volunteer 1 blood, UCN34 grew in the first $6 \mathrm{~h}$ of incubation, the titer then decreased for the next $18 \mathrm{~h}$, and increased again up to $4.1 \times 10^{6} \mathrm{CFU} / \mathrm{ml}$ at $48 \mathrm{~h}$ (Fig. 1a). In the blood of volunteer 2, UCN34 grew in the first $24 \mathrm{~h}$ (titer increased by a factor of 100), but the titer decreased after $48 \mathrm{~h}$ (Fig. 1b). In contrast, a continuous growth of this strain $\left(0 \mathrm{~h}: 1.6 \times 10^{5} \mathrm{CFU} / \mathrm{ml} ; 48 \mathrm{~h}\right.$ : $6.7 \times 10^{6} \mathrm{CFU} / \mathrm{ml}$ ) was observed in the whole blood of volunteer 3 (Fig. 1c). In Fig. 1d, we summarize the survival or growth of all strains in whole blood of all three volunteers. As seen, the titer of the strains DSM13808, BAA2069 and LMG17956 in all three volunteers blood lied between the titer of the strain UCN34 and the titer of DSM16831 after $48 \mathrm{~h}$ of incubation (Fig. 1d). The initial titer of these isolates was $2-4.8 \times 10^{5} \mathrm{CFU} / \mathrm{ml}$, which increased only slightly by a factor of about 10 within $48 \mathrm{~h}$.
Induction of IL-6 secretion by immune cells in whole blood after S. gallolyticus subsp. gallolyticus inoculation The survival of bacteria in whole blood is influenced by the inflammatory response of immune cells. Upon measuring the bacterial survival, we quantified the IL-6 concentration in whole blood supernatants, based on the premise that this will reflect the ability of different $S$. gallolyticus subsp. gallolyticus isolates to regulate the inflammatory response of the host, which may be relevant to bacterial escape of the innate immune system. Results (Fig. 2) show that after $6 \mathrm{~h}$ of incubation with the bacteria, only marginal divergences could be observed among the different study volunteers. Stronger individual variations were seen after 24 and $48 \mathrm{~h}$ incubations. Specifically, IL-6 induction in volunteer 1 was higher overall compared to volunteers 2 and 3, independent of the S. gallolyticus subsp. gallolyticus isolate used for the inoculation. Volunteer 2 elicited the lowest IL- 6 expression after 24 and $48 \mathrm{~h}$. The averaged IL- 6 values of all three individuals were then used to compare the straindependent induction of IL-6 synthesis (Fig. 1b). At $6 \mathrm{~h}$ post-incubation, the $S$. gallolyticus subsp. gallolyticus strain DSM16831 induced slightly higher amounts of IL-6 than the other strains. The capability of DSM16831 to induce IL-6 in whole blood was distinctly higher than that of BAA-2069 and LMG17956 (Fig. 1a; 175 pg/ml vs. $114 \mathrm{pg} / \mathrm{ml}$ ). At $24 \mathrm{~h}$, IL-6 secretion elicited by DSM16831 was also the highest (Fig. 2b), being about twice as high as those observed for the four other strains (e.g. volunteer 2: DSM16831: $959 \mathrm{pg} / \mathrm{ml}$, DSM13808:
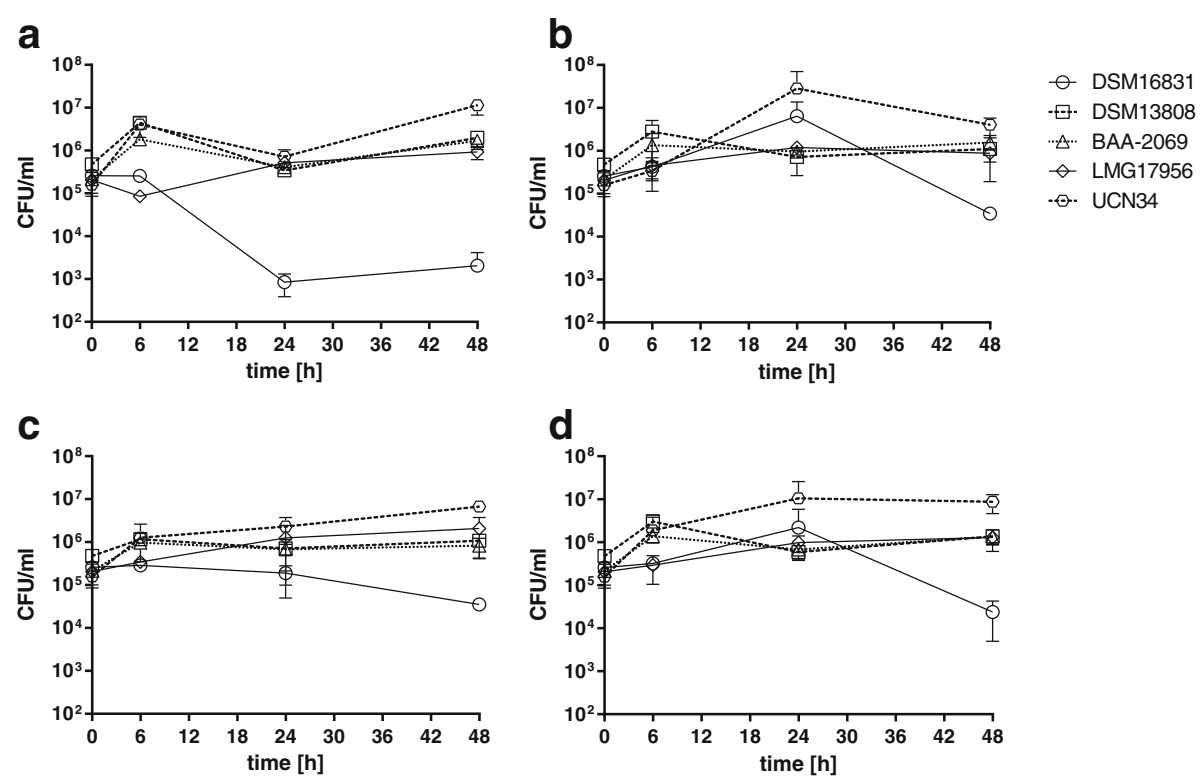

Fig. 1 Growth of S. gallolyticus subsp. gallolyticus strains in a whole blood model. Bacterial growth (with mean and standard deviation) of the S. gallolyticus subsp. gallolyticus strains DSM16831, DSM13808, BAA-2069, LMG17956 and UCN34 was determined in a whole blood model with blood from three different volunteers ( $n=2$ per volunteer), as described in Materials and Methods. The bacterial titers (CFU/ml) in each volunteer blood (a-c) and the merged (averaged) values of all (d) are displayed as indicated. Bacterial titer was determined by plating assay 


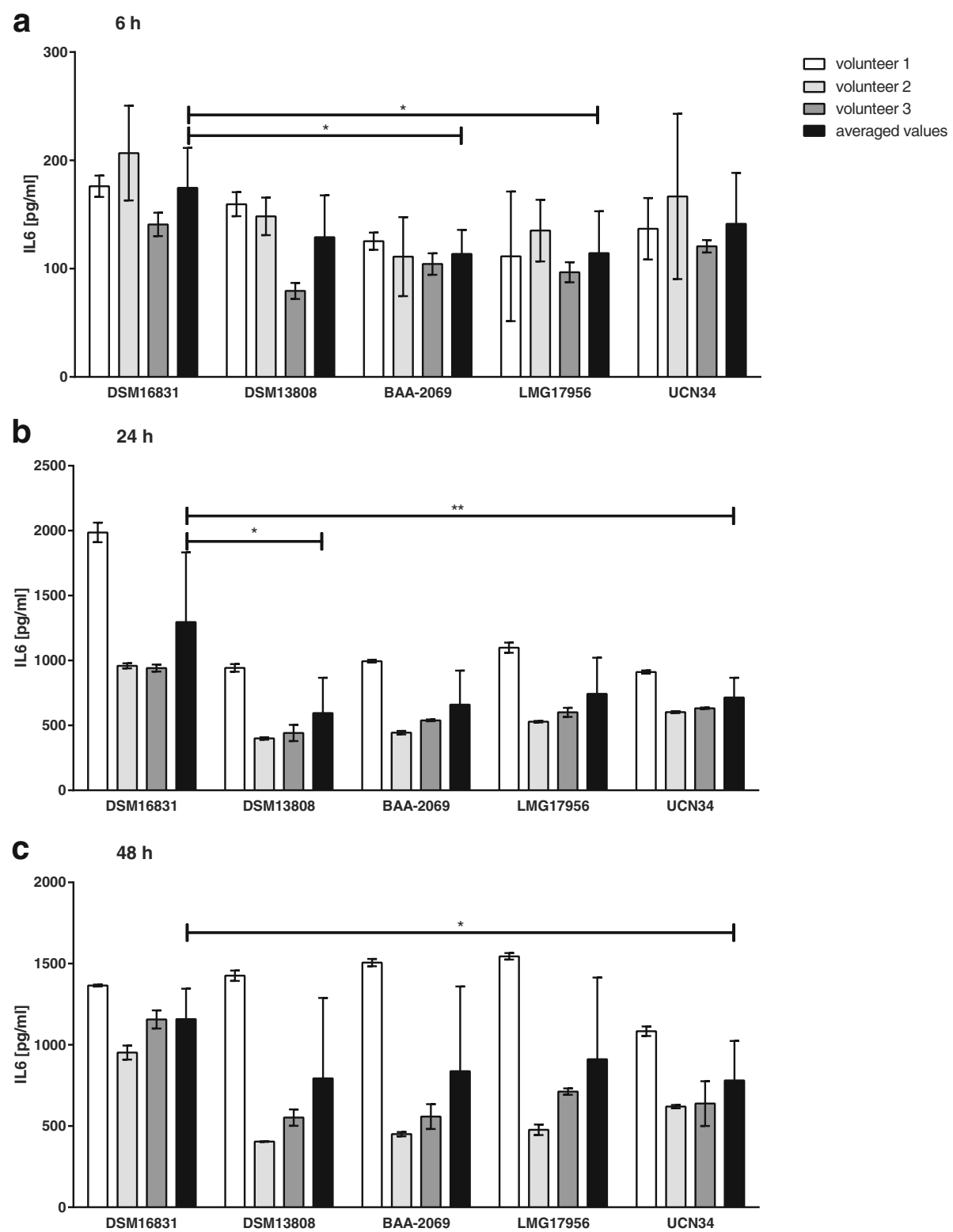

Fig. 2 Induction of IL6 in a whole blood model of S. gallolyticus subsp. gallolyticus strains. IL6 concentration (mean and standard deviation) after inoculation for 6 (a), 24 (b) and 48 h (c) with the S. gallolyticus subsp. gallolyticus strains DSM16831, DSM13808, BAA-2069, LMG17956 and UCN34 in a whole blood model of three different volunteers ( $n=2$ per volunteer), determined as described in Materials and Methods. The averaged IL6 concentration of all three volunteers (black bars) was used to demonstrate significant differences between the isolates (Mann-Whitney test, **: $p \leq 0.005 ;: p \leq 0.05)$

$400 \mathrm{pg} / \mathrm{ml}, \mathrm{BAA}-2069: 445 \mathrm{pg} / \mathrm{ml}$ and UCN34: $602 \mathrm{pg} /$ $\mathrm{ml})$. A decrease in the IL-6 concentration from 24 to $48 \mathrm{~h}$ of incubation of DSM16831 in the whole blood of volunteer 1 was also noted (Fig. 2c). By contrast, incubation with the other isolates and in the other volunteers showed an increase of the IL-6 concentration after $48 \mathrm{~h}$ compared to $24 \mathrm{~h}$. Taken together, these results revealed inter-individual differences as well as strain-dependency in IL-6 stimulation.
Induction of ILIB, IL6 and IL8 gene expressions in THP-1 monocytes by $S$. gallolyticus subsp. gallolyticus strains

Since monocytes are early-response immune cells that are recruited to the site of infection in IE and play an important role in inflammation, one can argue that $S$. gallolyticus subsp. gallolyticus would benefit from a reduced recruitment of monocytes and lower induction of inflammatory cytokines and chemokines. To test this in the absence of any influence of individual factors in 
blood, we used a cell culture model (THP-1 monocytes) and analyzed the stimulation potential of different S. gallolyticus subsp. gallolyticus strains. THP-1 cells were inoculated with $2.4-7.1 \times 10^{5} \mathrm{CFU} / \mathrm{ml}$ S. gallolyticus subsp. gallolyticus strains for $6 \mathrm{~h}$. We first determined the bacterial titer to exclude a potential difference in the stimulation of cytokine gene expression due to divergence in bacterial growth. As shown (Fig. 3a; right yaxes), 8 S. gallolyticus subsp. gallolyticus isolates grew to $5.7 \times 10^{6}-1.5 \times 10^{8} \mathrm{CFU} / \mathrm{ml}$ after $6 \mathrm{~h}$ of incubation. Only the bacterial titer of strain AC1181 decreased during the $6 \mathrm{~h}$ of incubation to $3 \times 10^{4} \mathrm{CFU} / \mathrm{ml}$.

We then quantified the expression of IL1B, IL6 and IL8 genes after induction with different $S$. gallolyticus subsp. gallolyticus isolates, using LTA $(25 \mu \mathrm{g} / \mathrm{ml})$ as positive control. Results (Fig. 3a-c) show that the induction of all three genes after inoculation with the S. gallolyticus subsp. gallolyticus strains AC1181 and isolate 010672/01 was lower compared to the induction by other strains. By contrast, the isolates DSM16831, 021702/06 and BAA-2069 induced 10-fold higher gene expression of IL1B, IL6 and IL8. The relative gene expression levels (arbitrary units: au) were: IL1B: DSM16831: 311, 021702/01: 340, BAA-2069: 440, 010672/01: 31, AC1181: 28; IL6: DSM16831: 608, 021702/01: 753, BAA-2069: 1172, 010672/01: 42, AC1181: 128; IL8: DSM16831: 56, 021702/01: 61, BAA2069: 50, 010672/01: 10, AC1181: 4.

Induction of platelet aggregation by S. gallolyticus subsp. gallolyticus

As mentioned earlier, platelet aggregation is a virulence factor of different Streptococcus species, and it was shown that S. gallolyticus subsp. gallolyticus promotes platelet aggregation as well [24]. To determine the interindividual variations of this property, we examined the induction of platelet aggregation by PRP of the same three volunteers that were recruited in the whole blood study, using light transmission aggregometry as described in Materials and Methods. The results (Fig. 4) show the comparison of strains for each volunteer (Fig. 4a-c) and averaged values of platelet aggregation of all three volunteers (Fig. 4d). It can be seen that the distribution of the summed values of all volunteers is very high in (Fig. 4d). Isolate 010672/01, for example, induced platelet aggregation during the inoculation of PRP of volunteer 1 after $741 \mathrm{~s}$ (Fig. 4a). By contrast, aggregation of platelets from volunteers 2 and 3 was not induced within $1800 \mathrm{~s}$ with this isolate (Fig. 4b and c). Similarly, isolate AC6827 induced aggregation of platelets of volunteer 2 only (Fig. 4b). It is also noteworthy that the platelets of volunteer 3 only aggregated after stimulation with the isolates DSM16831, DSM13808 and 021702/06 (Fig. 4c), while the other six isolates could not induce platelet aggregation. Clearly, the potential of S. gallolyticus subsp. gallolyticus to induce platelet aggregation depends highly on individual host factors.

Regardless of host specificity, the induction of platelet aggregation with the S. gallolyticus subsp. gallolyticus isolates AC6827 and LMG17956 was modest overall in all volunteers (Fig. 4d). By contrast, isolate DSM13808 induced platelet aggregation of the platelets of all three volunteers comparably rapidly after the start of inoculation (Fig. 4a-d; volunteer 1: $890 \mathrm{~s}$, volunteer 2: $547 \mathrm{~s}$, volunteer 3: $808 \mathrm{~s}$ ). The isolate BAA-2069 showed comparably quick induction of platelet aggregation of volunteer 1 and 2, while no induction of platelet aggregation was determined in the PRP of volunteer 3 (Fig. 4a-c).

\section{Strain-dependent phagocytosis of S. gallolyticus subsp. gallolyticus by macrophages}

Following survival in the human blood stream, S. gallolyticus subsp. gallolyticus needs to survive in the tissue of the endocardium. In this context, by far the most important cells of the innate immune system are the macrophages [17]. To analyze the clearance of S. gallolyticus subsp. gallolyticus by macrophages, the cells of the THP1 macrophage line were inoculated with five different $S$. gallolyticus subsp. gallolyticus isolates and the Staphylococcus aureus strain ATCC25923 (Fig. 5). This methicillin-sensitive Staphylococcus aureus isolate is used as a strain of comparison in different models of infectious diseases [30-32].

The number of phagocytized bacteria varied significantly between the $S$. gallolyticus subsp. gallolyticus isolates. Strain DSM16831 (5.41\%), DSM13808 (10.9\%) and UCN34 (17.2\%) were phagocytized by almost the same amount. The strain BAA-2069 was phagocytized significantly higher (BAA-2069: 29.5\%) by THP-1 macrophages, whereas only $1.4 \%$ of the inoculum of AC6827 given was found in the macrophages. All S. gallolyticus subsp. gallolyticus isolates were less phagocytized than Staphylococcus aureus.

The bacterial titer was determined at different time points within $48 \mathrm{~h}$ to investigate whether bacteria were destroyed inside the macrophages. The survival of the $S$. gallolyticus subsp. gallolyticus isolates and of the Staphylococcus aureus isolate ATCC25923 is shown in Fig. 6. All S. gallolyticus subsp. gallolyticus isolates and the Staphylococcus aureus isolate were continuously eliminated, however, only the isolates BAA-2069 and UCN34 showed a constant titer between 12 and $16 \mathrm{~h}$ or 8 and $16 \mathrm{~h}$.

\section{Discussion}

This study elucidated strain-dependent divergences regarding several potential pathogenic pathways of S. gallolyticus subsp. gallolyticus-induced infections, the 


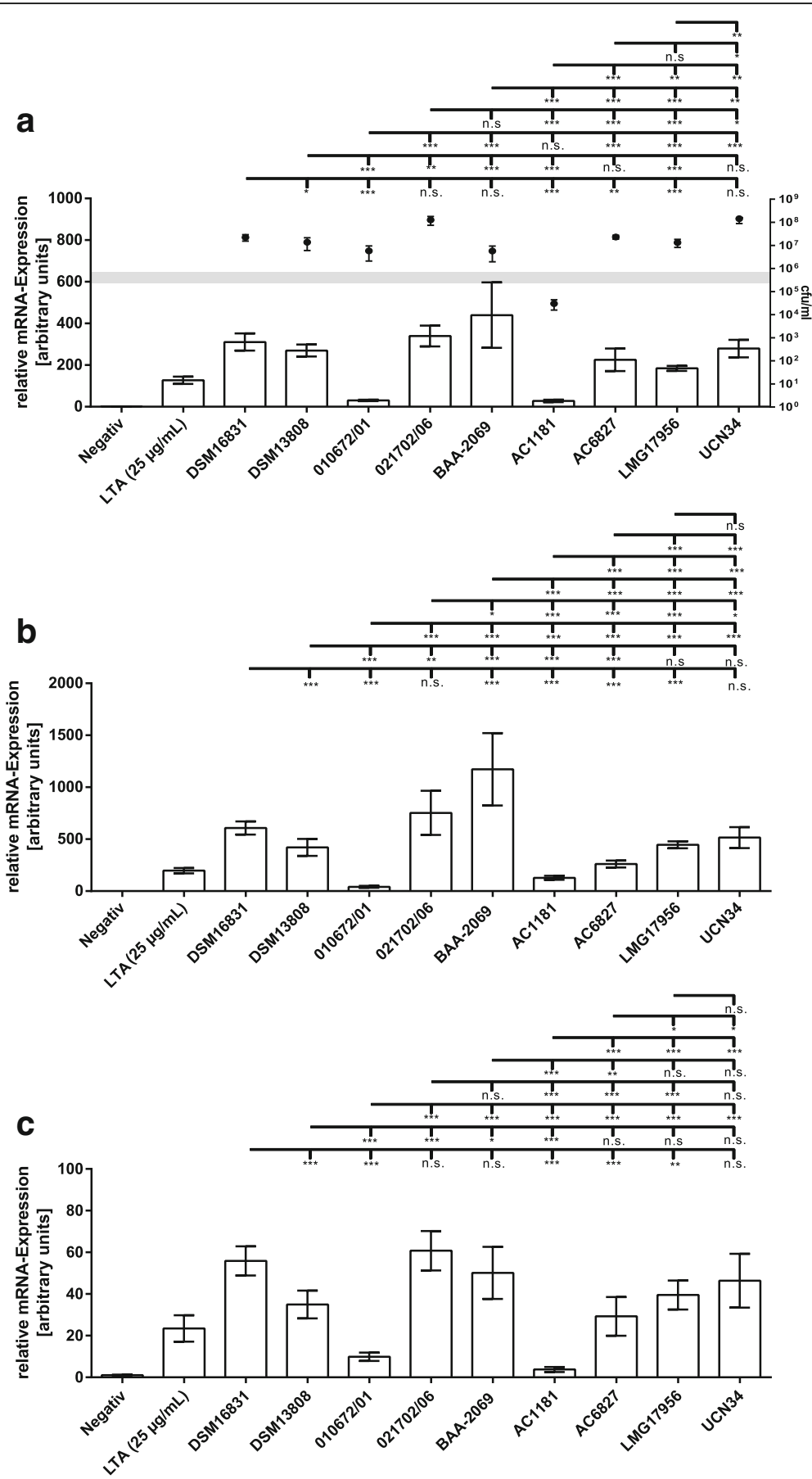

Fig. 3 Bacterial titer and induction of gene expression of $I L 1 B(\mathbf{a}), I L 6(\mathbf{b})$ and $I L 8$ (c). THP-1 cells were inoculated with $2.4-7.1 \times 10^{5}$ CFU/ml of S. gallolyticus subsp. gallolyticus strains. After $6 \mathrm{~h}$ of inoculation, the bacterial titer was determined by plating assay in triplicate $(n=3)$ and displayed as black dots in panel A. The bacterial titers are shown on the right-hand $y$-axis, and the horizontal grey line represents the input titer. LTA $(25 \mu \mathrm{g} / \mathrm{ml})$ and media were used as positive and negative controls, respectively (bars; $\mathrm{n}=3$ ). After $6 \mathrm{~h}$ of inoculation, the relative gene expression of ILIB, IL6 and IL8 was determined using real-time PCR. Comparison of induction between the isolates (lines above the bars) was performed using the Mann-Whitney test (n.s: not significant, ${ }^{*}: p \leq 0.05,{ }^{* *}: p \leq 0.005,{ }^{* * *}: p \leq 0.0005$ )

results of which can provide the basis for future studies of pathogenesis by this bacterium and its various strains. Through systematic review and meta-analysis, Boleij et al. (2011) proposed that S. gallolyticus subsp. gallolyticus translocates paracellularly through malignant colonic lesions into the bloodstream [5]. We reasoned that the pathomechanisms of the process must involve survival of the bacteria within the bloodstream as well as 


\section{a}

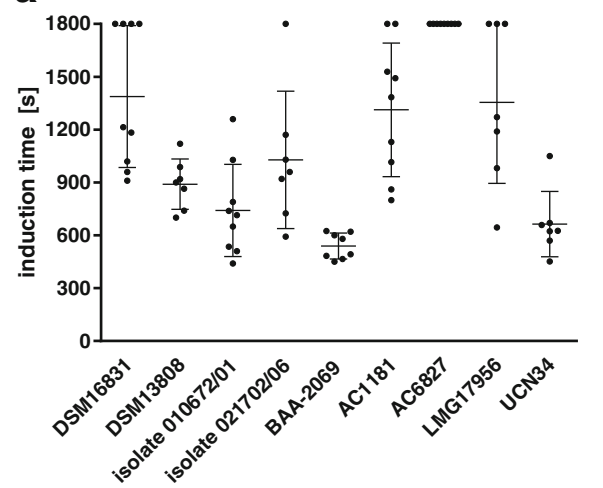

C

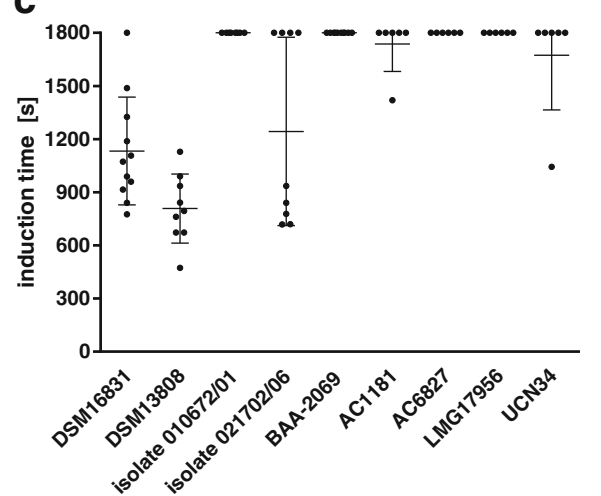

b

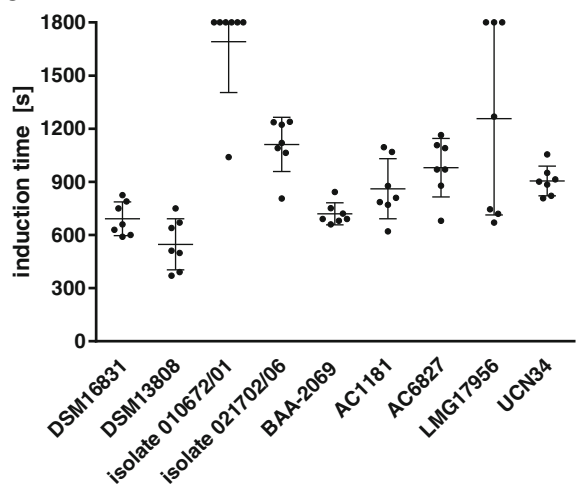

d

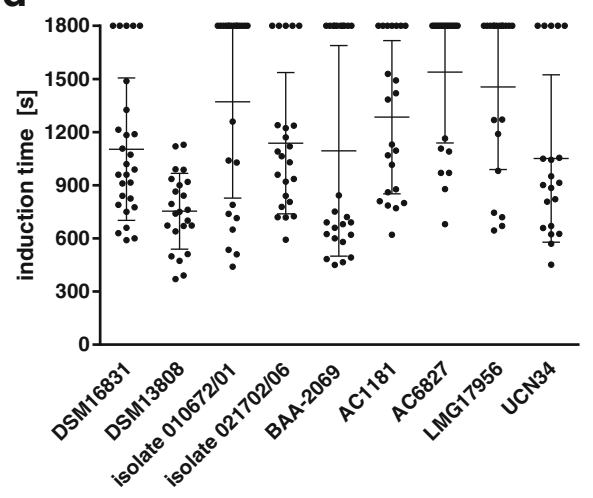

Fig. 4 Induction time of platelet aggregation with S. gallolyticus subsp. gallolyticus strains. The PRPs of three volunteers (a-c) were inoculated with the indicated S. gallolyticus subsp. gallolyticus strains. The induction times of the strains to promote platelet aggregation in all three volunteers are summed up in panel $\mathbf{d}$. The time to induce a detectable platelet aggregation was determined using light transmission aggregation (BORN method; $\mathrm{n}=3$ ), as described in Materials and Methods. Value obtained with a sample in which no platelet aggregation was induced is listed and set at $1800 \mathrm{~s}$

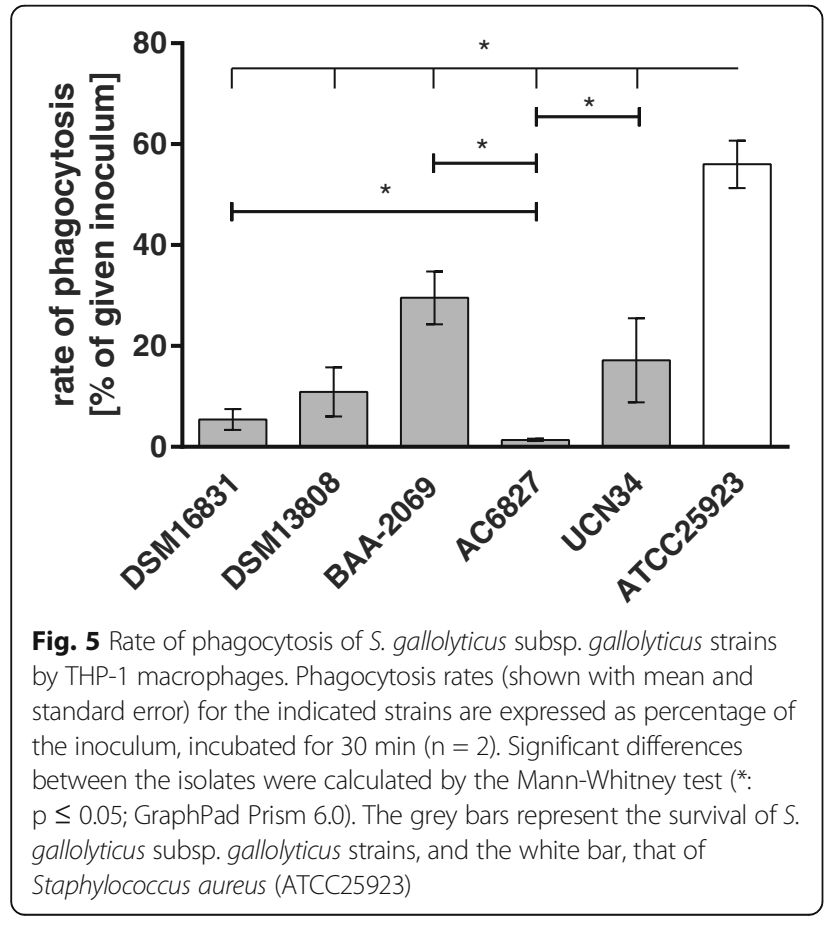

adherence, persistence and proliferation at the endocardium [33]. Thus, we initiated a comprehensive analysis relevant to various steps of the process. To summarize, we first analyzed bacterial growth and survival in a whole blood model. We then focused on the response of immune cells to different $S$. gallolyticus subsp. gallolyticus isolates, whereby we quantified the protein and mRNA of strategic cytokines and chemokines. We also studied platelet aggregation, since in addition to survival against innate immunity, induction of platelet aggregation plays a major role in bacterial colonization at the endocardium as it masks the pathogen against immune cells of the human blood [34].

We have shown that the growth characteristics in the whole blood model differed between the S. gallolyticus subsp. gallolyticus isolates. Difference in cell viability in blood, stimulated by different $S$. gallolyticus subsp. gallolyticus strains, was not observed by flow cytometric analysis, but $S$. gallolyticus subsp. gallolyticus-stimulated blood showed a reduction of granulocytes compared to the control with no bacteria. This is due most probably to phagocytic uptake by and apoptosis of these cells $[35,36]$. 

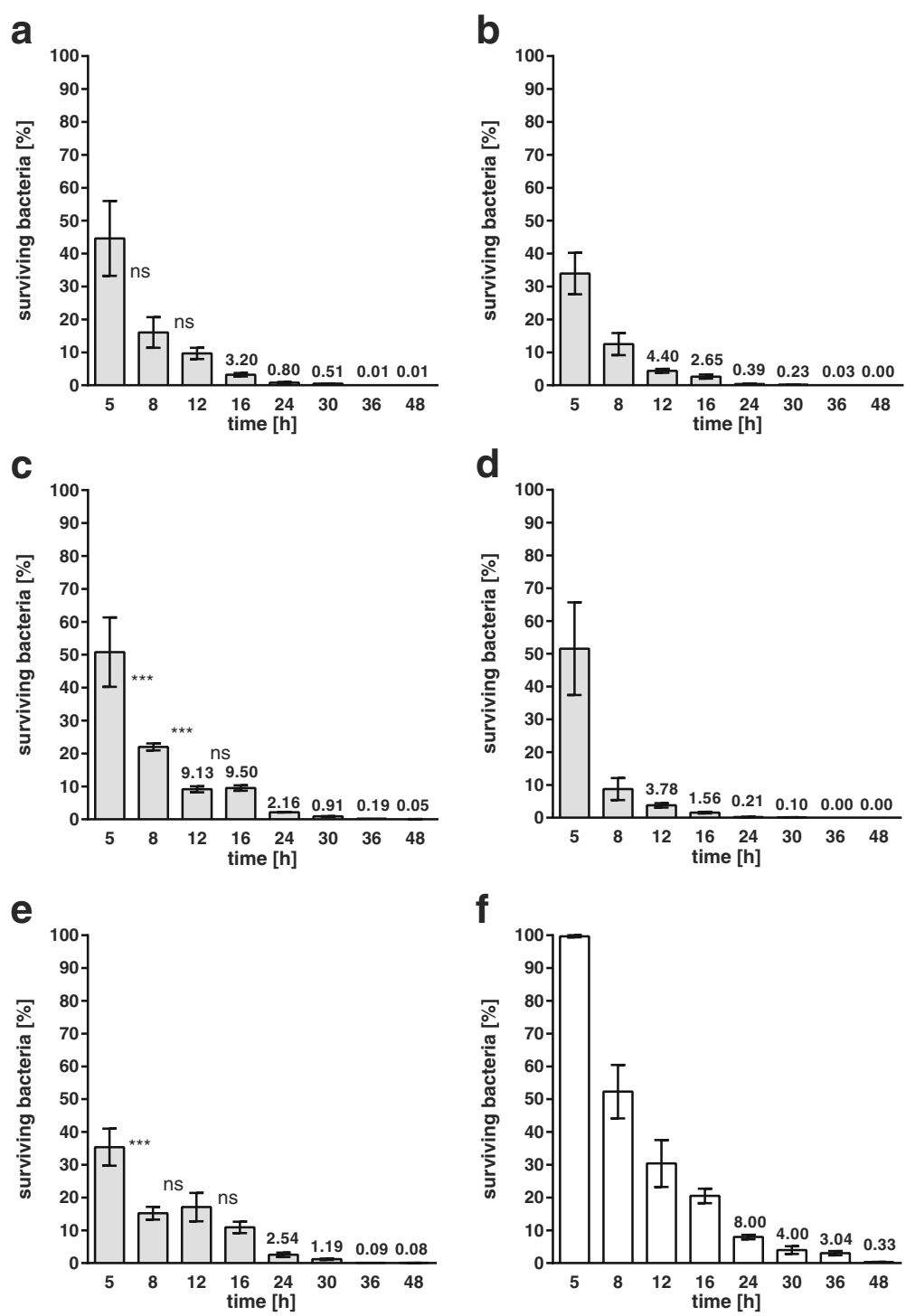

Fig. 6 Survival of S. gallolyticus subsp. gallolyticus strains in macrophages. Percentage of surviving bacteria after $48 \mathrm{~h}$ of phagocytosis is shown for DSM16831 (a), DSM13808 (b), BAA-2069 (c), AC6827 (d) and UCN34 (e) and the Staphylococcus aureus strain ATCC25923 (f) (mean with standard error, relative to the bacterial titer at $t=0 \mathrm{~h}$ ). The grey bars represent $\mathrm{S}$. gallolyticus subsp. gallolyticus strains and the white bars represent Staphylococcus aureus $(n=2)$

In our analysis of the inflammatory response of THP-1 monocytes to different S. gallolyticus subsp. gallolyticus strains, we analyzed the gene expression of the early cytokine TNF- $\alpha$ and the later chemokine MCP-1, whereby the same expression patterns were detected as shown for the genes IL1 $\beta, I L 6$ and IL8 (data not shown). Stimulation of THP-1 monocytes with the isolates DSM16831 and BAA-2069 led to the highest increase in expression of the IL1B, IL6 and IL8 genes, whereas the isolates $010672 / 01$ and AC1181 led only to a marginal increase in gene expression of these cytokines. Although we do not know the exact reason for the difference, at least in the case of AC1181, the lower response can be due to a dose-effect relationship. Specifically, in studies of the bacterial titer in the presence of THP-1 monocytes, AC1181 showed a decrease in the multiplicity of infection after $6 \mathrm{~h}$ of incubation, which could be potentially due to phagocytosis and killing through monocytes [37]. In case of the isolate $010672 / 01$, however, the induction of the cytokine gene expression was low even though the titer was comparable to those of the other strains.

There is evidence that the absence of IL- 6 in the early stage of an IE leads to a higher mortality in mouse [13]. Moreover, it was also shown that a decrease in IL-6 secretion leads to a higher survival of mice with sepsis 
[12]. Our data confirmed that IL-6 secretion in S. gallolyticus subsp. gallolyticus infection depends on both the strain and the individual blood. As summarized in Table 3, DSM16831 caused an early immune response followed by an early elimination in whole blood, whereas UCN34 could grow without a strong activation of the immune system. It is likely that the difference is due to different surface proteins and teichoic acids that may be involved in bacteria-host recognition and resultant signaling, such that DSM16831 is more efficiently recognized by the host immune cells, leading to a higher immune response and more rapid bacterial killing. Evidently, an analysis of the bacterial surface in these strains may lead to a better understanding of the recognition process and the resultant phenotypes.

In addition to the survival in blood, persistence and colonization at the endocardium are required for successful infection [33]. Survival in phagocytic cells (such as macrophages) and the platelet aggregation can, on one hand, act bactericidally, but on the other hand, may also mask the bacteria by forming vegetation. For this reason, we have studied both processes in multiple bacterial isolates. As we have shown, the rate of phagocytosis of DSM16831 was low; additionally, this strain was degraded continuously in macrophages, which is in contrast to the strains BAA-2069 and UCN34. The phenotype of DSM16831 implies overall low virulence, since DSM16831 was also not able to invade endothelial cells in vitro in contrast to many other S. gallolyticus subsp.

Table 3 Summarized results of the blood assay and platelet aggregation. The outcome is scaled from killed bacterial cells, low IL-6 secretion by blood cells and no stimulation of platelet aggregation to growth in blood, high IL-6 secretion and fast platelet aggregation by these symbols: ---/--/ $-/ 0 /+/++/+++$

\begin{tabular}{lllll}
\hline & & Volunteer 1 & Volunteer 2 & Volunteer 3 \\
\hline DSM16831 & Blood survival & -- & 0 & 0 \\
& IL6 conc. (48 h) & +++ & ++ & ++ \\
& Aggregation & - & + & - \\
DSM13808 & Blood survival & + & + & + \\
& IL6 conc. (48 h) & + & 0 & 0 \\
& Aggregation & 0 & + & 0 \\
BAA-2069 & Blood survival & + & + & + \\
& IL6 conc. (48 h) & + & 0 & 0 \\
& Aggregation & + & + & -- \\
LMG17956 & Blood survival & + & + & + \\
& IL6 conc. (48 h) & + & 0 & 0 \\
& Aggregation & -- & -- & -- \\
UCN34 & Blood survival & ++ & ++ & ++ \\
& IL6 conc. (48 h) & + & 0 & 0 \\
\hline & Aggregation & + & 0 & -- \\
\hline
\end{tabular}

gallolyticus strains tested [7]. The ability of UCN34 and BAA-2069 to survive in macrophages for a certain time clearly presents a potentially important advantage. In fact, this phenotype has already been determined as a high virulence characteristic for Staphylococcus aureus and S. mutans [38, 39].

De Herdt et al. (1995) observed intracellular replication of distinct $S$. bovis strains after phagocytosis by macrophages from pigeons, which also induced lysis of all macrophages after $7 \mathrm{~h}$ of incubation [40]. We did not observe this phenotype of $S$. bovis in the primary macrophages for S. gallolyticus subsp. gallolyticus in the macrophage-like THP-1 cells, as only $20 \%$ of the macrophages were lysed after $24 \mathrm{~h}$, regardless of whether the strain was highly or modestly phagocytized. While persisting in macrophages and endothelial cells [7], the $S$. gallolyticus subsp. gallolyticus strains UCN34 and BAA2069 could have an advantage over other strains in, for example, antibiotic treatment, resulting in better persistence in tissue and blood. Based on these results, we performed a transcriptome analysis of S. gallolyticus subsp. gallolyticus following phagocytosis by THP-1 macrophages. This revealed that S. gallolyticus subsp. gallolyticus reacts probably to oxidative burst with a higher gene expression of NADH oxidase directly after phagocytosis. Five hours after phagocytosis, the gene expression of Dlt-proteins, which are required for D-alanylation of teichoic acids, and proteins involved in carbohydrate metabolism and transport systems were upregulated [41]. Danne et al. (2014) presented a linkage between pili expression of the strain UCN 34 and phagocytosis, thereby showing a higher phagocytosis of highly piliated bacterial cells. In addition, genotypic differences regarding the pilB gene between strains could also influence IL-6 induction and survival in whole blood [42] Interestingly, DSM16831 and AC6827 lack the gene pilB and also show a weak intracellular uptake through phagocytosis [7]. This correlation should be analyzed with other strains with and without the pilB gene to understand the mechanism of differences in bacterial uptake by phagocytosis.

In this study, we have clearly documented high individual variances in different $S$. gallolyticus subsp. gallolyticus isolates to induce platelet aggregation. While DSM13808 led to considerably higher aggregation, the isolates LMG17956 and AC6827 were weaker agents (Table 3). Conceivably, such induction potential can be highly relevant to the pathogenicity of strains for causing IE in vivo. In corollary, mediators of platelet aggregation by $S$. gallolyticus subsp. gallolyticus can be considered virulence factors in IE. Future studies may reveal the identity of the factors, but it is tempting to speculate that the interactions between platelets and S. gallolyticus subsp. gallolyticus is mediated by platelet receptors, such 
as GPIb or GPIIb/IIIa, as was shown for other bacteria, such as Staphylococcus aureus or Streptococcus sanguinis $[23,43]$.

S. gallolyticus subsp. gallolyticus strains show very different characteristics in survival and stimulation potential with regard to human blood cells. Unfortunately, a direct comparison between human pathogenic isolates and those from non-human sources is not possible. Nevertheless, it is worth noting that the human IE isolate UCN34 showed a high virulent phenotype whereas the strain DSM16831 from koala feces showed a low virulent phenotype [7]. On the other hand, DSM13808, collected from sapropel (not associated with infection) led to fast platelet aggregation (high virulence factor) but had a moderate phenotype in other analyses, compared to other strains. Additionally, our results show comparable phenotypes between the strains BAA-2069, isolated from an IE-patient, and LMG17956, isolated from calf. However, BAA-2069 induced the aggregation of platelets earlier than LMG17956. Thus, genetic information, such as distinct sequence types revealed by multilocus sequence typing could not be correlated with observed phenotypes [44]. Because of these different characteristics in phenotypic experiments versus genotype of each strain, it is unfeasible to assign the origin to the strains methodically $[7,44]$. This has also led to the hypothesis that $S$. gallolyticus subsp. gallolyticus has the potential for zoonosis and may transmit from animal to human and vice versa [45].

In addition to the bacterial strain-dependent influence, interindividual variations in responses to the bacteria also influence an IE. Genetic predispositions to IE and platelet aggregation have already been found [46, 47]. Individual host responses to the S. gallolyticus subsp. gallolyticus isolates were observed in this study in whole blood and platelet aggregation, whereby blood from the same volunteers was used for both assays for unambiguous comparison. The high inter-individual divergences of platelet aggregation observed was also described for stimulation by Streptococcus sanguinis [48]. Finally, platelet aggregation by pathogens is likely an important virulence factor that promotes IE establishment, and hence, it will be quite interesting to identify the host factors that underlie the relevant interactions [49].

\section{Conclusions}

Our results presented here have contributed to uncover the nature of the phenotypes of S. gallolyticus subsp. gallolyticus strains in vitro, which may influence the infection process in vivo. The DSM16831 isolate remains particularly interesting, because of its very low virulent phenotype in vitro and likely poor survival in tissue and blood compared to the other isolates tested (e.g. UCN34 and BAA-2069). These findings will form the foundation for further research that should provide a more detailed knowledge of the pathogenicity factors of S. gallolyticus subsp. gallolyticus isolates that contribute to divergent phenotypes. The results should enhance our understanding of pathophysiological interrelationship between these factors and the establishment of IE that leads to congestive heart failure.

\section{Abbreviations \\ AB/AM: Antibiotic/antimycotic solution; Au: Arbitrary units; CFU: Colony- forming units; DPBS: Dulbecco's phosphate-buffered saline; FCS: Fetal calf serum; IE: Infective endocarditis; IL: Interleukin; LDH: Lactate dehydrogenase; LTA: Lipoteichoic acid; PRP: platelet-rich plasma}

\section{Acknowledgements}

We thank Philip Saunders and EonBio for their linguistic advice. We also acknowledge Ruhr-Universität Bochum for providing the DFG Open Access Publication Fund.

\section{Funding}

This research was supported by the DFG Open Access Publication Funds of the Ruhr-Universität Bochum.

\section{Availability of data and materials}

The dataset is available from the corresponding author and can be obtained on reasonable request.

\section{Authors' contributions}

MW and IG conducted macrophage cell culture model, analyzed the data and wrote the paper. MW performed the whole blood assay and platelet aggregation. JDr and IB participated in planning the experiments. CK and TV initiated and coordinated the study, planned the experimental designs, and contributed to the writing of the paper. All authors read and approved the final manuscript.

\section{Ethics approval and consent to participate}

The study protocol was approved by the institutional review board of the Ruhr University of Bochum, and healthy volunteers provided informed written consent.

\section{Consent for publication}

Not applicable

\section{Competing interests}

The authors declare that they have no competing interests.

\section{Publisher's Note}

Springer Nature remains neutral with regard to jurisdictional claims in published maps and institutional affiliations.

Received: 27 March 2017 Accepted: 18 October 2017

Published online: 27 October 2017

\section{References}

1. Schlegel L, Grimont F, Ageron E, Grimont PA, Bouvet A. Reappraisal of the taxonomy of the Streptococcus bovis/Streptococcus equinus Complex and related species: description of Streptococcus gallolyticus subsp. gallolyticus subsp. nov., S. gallolyticus subsp. macedonicus subsp. nov. and S. gallolyticus subsp. pasteurianus subsp. nov. Int J Syst Evol Microbiol. 2003;53:631-45.

2. Abeni C, Rota L, Ogliosi C, Bertocchi P, Centurini PB, Zaniboni A. Correlation among Streptococcus bovis, endocarditis and septicemia in a patient with advanced colon cancer: a case report. J Med Case Rep. 2013;7:185.

3. Abdulamir AS, Hafidh RR, Bakar FA. Others: the association of Streptococcus bovis/gallolyticus with colorectal tumors: the nature and the underlying mechanisms of its etiological role. J Exp Clin Cancer Res. 2011;30:11.

4. Lazarovitch T, Shango M, Levine M, Brusovansky R, Akins R, Hayakawa K, Lephart P, Sobel J, Kaye K, Marchaim D. The relationship between the new taxonomy of Streptococcus bovis and its clonality to colon cancer, endocarditis, and biliary disease. Infection. 2013;41:329-37. 
5. Boleij A, Muytjens CMJ, Bukhari SI, Cayet N, Glaser P, Hermans PWM, Swinkels DW, Bolhuis A, Tjalsma H. Novel clues on the specific association of Streptococcus gallolyticus subsp gallolyticus with colorectal cancer. J Infect Dis. 2011:203:1101-9.

6. Sillanpää J, Nallapareddy SR, Singh KV, Ferraro MJ, Murray BE. Adherence characteristics of endocarditis-derived Streptococcus gallolyticus ssp. gallolyticus (Streptococcus bovis biotype I) isolates to host extracellular matrix proteins. FEMS Microbiol Lett. 2008;289:104-9.

7. Vollmer T, Hinse D, Kleesiek K, Dreier J. Interactions between endocarditisderived streptococcus gallolyticus subsp. gallolyticus isolates and human endothelial cells. BMC Microbiol. 2010;10:78.

8. Aderem A, Underhill DM. Mechanisms of phagocytosis in macrophages. Annu Rev Immunol. 1999:17:593-623.

9. Tsigou E, Stavros A, Pavlos M, Stavros G, Athanassios T, George B. The immune response after stimulation with wall components of gram-positive bacteria and fungi. Immunol Lett. 2014;159:23-9.

10. Hessle CC, Andersson B, Wold AE. Gram-positive and gram-negative bacteria elicit different patterns of pro-inflammatory cytokines in human monocytes. Cytokine. 2005:30:311-8.

11. Kanda T, Takahashi T. Interleukin-6 and cardiovascular diseases. Jpn Heart J. 2004:45:183-93.

12. Riedemann NC, Neff TA, Guo R-F, Bernacki KD, Laudes IJ, Sarma JV, Lambris JD, Ward PA. Protective effects of IL-6 blockade in sepsis are linked to reduced C5a receptor expression. J Immunol. 2003;170:503-7.

13. Shun C-T, Lu S-Y, Yeh C-Y, Chiang C-P, Chia J-S, Chen J-Y. Glucosyltransferases of viridans streptococci are modulins of interleukin-6 induction in infective endocarditis. Infect Immun. 2005;73:3261-70.

14. Bustamante J, Arévalo A, Tamayo E, Sarria C, Aguilar-Blanco EM, Heredia M, Almansa R, Rico L, Iglesias V, Bermejo-Martin JF. Cytokine profiles linked to fatal outcome in infective prosthetic valve endocarditis. APMIS. 2014;122:526-9.

15. Deviri E, Glenville B. Inflammatory response in infective endocarditis. Eur J Inflamm. 2007:5:57-63.

16. Yang J, Zhang L, Yu C, Yang X-F, Wang H. Monocyte and macrophage differentiation: circulation inflammatory monocyte as biomarker for inflammatory diseases. Biomark Res. 2014;2:1

17. Benoit M, Thuny F, Le Priol Y, Lepidi H, Bastonero S, Casalta J-P, Collart F, Capo C, Raoult D, Mege J-L. The transcriptional programme of human heart valves reveals the natural history of infective endocarditis. PLoS One. 2010;5:e8939.

18. Scheller J, Chalaris A, Schmidt-Arras D, Rose-John S. The pro- and antiinflammatory properties of the cytokine interleukin-6. Biochim Biophys Acta. 1813:2011:878-88.

19. Shi C, Pamer EG. Monocyte recruitment during infection and inflammation. Nat Rev Immunol. 2011;11:762-74.

20. Widmer E, Que Y-A, Entenza JM, Moreillon P. New concepts in the pathophysiology of infective endocarditis. Curr Infect Dis Rep. 2006:8:271-9.

21. Ford I, Douglas CW. The role of platelets in infective endocarditis. Platelets. 1997:8:285-94

22. Heilmann C, Niemann S, Sinha B, Hermann M, Kehrel BE, Peters G. Staphylococcus aureus Fibronectin-binding protein (FnBP)—mediated adherence to platelets, and aggregation of platelets induced by FnBPA but not by FnBPB. J Infect Dis. 2004;190:321-9.

23. Yeaman MR. Platelets in defense against bacterial pathogens. Cell Mol Life Sci. 2010:67:525-44.

24. Veloso TR, Oechslin F, Que Y-A, Moreillon P, Entenza JM, Mancini S. Aspirin plus ticlopidine prevented experimental endocarditis due to Enterococcus faecalis and Streptococcus gallolyticus. Pathog Dis. 2015;73:ftv060.

25. Liu M, Hanks TS, Zhang J, McClure MJ, Siemsen DW, Elser JL, Quinn MT, Lei B. Defects in ex vivo and in vivo growth and sensitivity to osmotic stress of group a Streptococcus caused by interruption of response regulator gene vicR. Microbiology. 2006;152:967-78.

26. Vandesompele J, De Preter K, Pattyn F, Poppe B, Van Roy N, De Paepe A, Speleman F: Accurate normalization of real-time quantitative RT-PCR data by geometric averaging of multiple internal control genes. Gen Biol 2002, 3:1

27. GVR B. Others: aggregation of blood platelets by adenosine diphosphate and its reversal. Nature. 1962;194:927-9.

28. Dreier J, Vollmer T, Kleesiek K. Novel flow Cytometry-based screening for bacterial contamination of donor platelet preparations compared with other rapid screening methods. Clin Chem. 2009;55:1492-502.
29. Kaneko M, Emoto Y, Emoto M. A simple, reproducible, inexpensive, yet oldfashioned method for determining Phagocytic and bactericidal activities of macrophages. Yonsei Med J. 2016;57:283-90.

30. Affhan S, Dachang W, Xin Y, Shang D. Lactic acid bacteria protect human intestinal epithelial cells from Staphylococcus aureus and Pseudomonas aeruginosa infections. Genet Mol Res. 2014;14:17044-58.

31. Cahill TJ, PB D. Infective endocarditis. Lancet. 2016:387:882-93.

32. Wu X, Jiang $H, X u Y$, Yue W, Yang L, Song Z, Chen H, Liu T. Efficacy of gemifloxacin for the treatment of experimental Staphylococcus aureus keratitis. J Ocul Pharmacol Ther. 2012;28:420-7.

33. Werdan K, Dietz S, Löffler B, Niemann S, Bushnaq H, Silber R-E, Peters G, Müller-Werdan U. Mechanisms of infective endocarditis: pathogen-host interaction and risk states. Nat Rev Cardiol. 2014;11:35-50.

34. Cox D, Kerrigan SW, Watson SP. Platelets and the innate immune system: mechanisms of bacterial-induced platelet activation. J Thromb Haemost. 2011;9:1097-107.

35. Colotta F, Re F, Polentarutti N, Sozzani S, Mantovani A. Modulation of granulocyte survival and programmed cell death by cytokines and bacterial products. Blood. 1992;80:2012-20.

36. Kobayashi SD, Voyich JM, Burlak C, DeLeo FR. Neutrophils in the innate immune response. Arch Immunol Ther Exp. 2005;53:505.

37. Underhill DM, Ozinsky A. Phagocytosis of microbes: complexity in action. Annu Rev Immunol. 2002;20:825-52.

38. Ding Y, Liu X, Chen F, Di H, Xu B, Zhou L, Deng X, Wu M, Yang C-G, Lan L. Metabolic sensor governing bacterial virulence in Staphylococcus aureus. Proc Natl Acad Sci U S A. 2014:111:E4981-90.

39. Jung C-J, Zheng Q-H, Shieh Y-H, Lin C-S, Chia J-S. Streptococcus mutans autolysin AtIA is a fibronectin-binding protein and contributes to bacterial survival in the bloodstream and virulence for infective endocarditis. Mol Microbiol. 2009;74:888-902.

40. De Herdt P, Haesebrouck F, Charlier G, Ducatelle R, Devriese LA, Vandenbossche G: Intracellular survival and multiplication of virulent and less virulent strains of Streptococcus bovis in pigeon macrophages. Vet Microbiol 1995, 45:157-169.

41. Grimm I, Garben N, Dreier J, Knabbe C, Vollmer T. Transcriptome analysis of Streptococcus gallolyticus subsp. gallolyticus in interaction with THP-1 macrophage-like cells. PLoS One. 2017;12:e0180044.

42. Danne C, Dubrac S, Trieu-Cuot P, Dramsi S. Single cell stochastic regulation of Pilus phase variation by an attenuation-like mechanism. PLoS Pathog. 2014;10:e1003860

43. Kerrigan SW, Douglas I, Wray A, Heath J, Byrne MF, Fitzgerald D, Cox D. A role for glycoprotein lb in Streptococcus sanguis-induced platelet aggregation. Blood. 2002;100:509-16.

44. Dumke J, Hinse D, Vollmer T, Knabbe C, Dreier J. Development and application of a multilocus sequence typing scheme for Streptococcus gallolyticus subsp. gallolyticus. J Clin Microbiol. 2014;52(7):2472-8.

45. Dumke J, Hinse D, Vollmer T, Schulz J, Knabbe C, Dreier J. Potential transmission pathways of streptococcus gallolyticus subsp. gallolyticus. PLoS One. 2015;10:e0126507.

46. Kunicki TJ, Nugent DJ. The genetics of normal platelet reactivity. Blood. 2010;116:2627-34.

47. Weinstock M, Grimm I, Dreier J, Knabbe C, Vollmer T. Genetic variants in genes of the inflammatory response in association with infective endocarditis. PLoS One. 2014:9:e110151.

48. McNicol A, Agpalza A, Jackson ECG, Hamzeh-Cognasse H, Garraud O, Cognasse F. Streptococcus sanguinis-induced cytokine release from platelets. J Thromb Haemost. 2011;9:2038-49.

49. Herzberg MC, MacFarlane GD, Gong K, Armstrong NN, Witt AR, Erickson PR, Meyer MW. The platelet interactivity phenotype of Streptococcus sanguis influences the course of experimental endocarditis. Infect Immun. 1992:60:4809-18.

50. Rusniok C, Couvé E, Da Cunha V, El Gana R, Zidane N, Bouchier C, Poyart C, Leclercq R, Trieu-Cuot P, Glaser P. Genome sequence of Streptococcus gallolyticus: insights into its adaptation to the bovine rumen and its ability to cause endocarditis. J Bacteriol. 2010;192:2266-76.

51. Treangen TJ, Maybank RA, Enke S, Friss MB, Diviak LF, Karaolis DKR, Koren S, Ondov B, Phillippy AM, Bergman NH, Rosovitz MJ. Complete genome sequence of the quality control strain Staphylococcus Aureus subsp. aureus ATCC 25923. Genome Announc. 2014;2(6):e01110. 